\title{
PERCEPÇÃO DOS MORADORES E AVALIAÇÃO DA ARBORIZAÇÃO EM BAIRROS PERIFÉRICOS NA CIDADE DE LAGES, SC
}

\author{
Aline Gross ${ }^{1}$; Priscilla Dors ${ }^{2}$; Karoline Andrade de Campos ${ }^{3}$; Ana Carolina da Silva ${ }^{4}$; Pedro Higuchi ${ }^{5}$
}

\section{RESUMO}

Este estudo objetivou avaliar a percepção dos moradores em relação à arborização de três bairros localizados na região periférica da cidade de Lages, SC, e quantificar e qualificar a arborização nestes bairros. Para isso, foram amostradas ruas nestes bairros (28,6\% das ruas do Caravágio, 24,1\% do Gethal e 25,0\% da Penha) nas quais foram sorteadas residências onde foram aplicados questionários com perguntas objetivas e dissertativas, com intuito de avaliar a percepção da arborização urbana pelos moradores. Nas ruas sorteadas também foi feita a avaliação da arborização, identificando, mensurando e avaliando os indivíduos arbóreos encontrados. Em geral, a percepção que os moradores dos três bairros avaliados têm sobre a arborização urbana é que esta é pouca à razoável. Apesar dos moradores reconhecerem algumas desvantagens da arborização, estes reconhecem sua importância sobre o bem-estar e estão insatisfeitos com a atuação do Poder Público Municipal, sugerindo maior investimento no lazer. Na avaliação da arborização foi encontrada baixa riqueza de espécies e uma ampla utilização de espécies exóticas, principalmente de Ligustrum lucidum W.T. Aiton., espécie invasora de áreas naturais. É necessária a melhoria da arborização urbana tanto na quantidade como na qualidade, priorizando a utilização de espécies nativas da região.

Palavras-chave: Arborização urbana; Ligustrum lucidum; Riqueza de espécies.

\section{RESIDENT'S PERCEPTIONS AND EVALUATION OF THE URBAN TREES IN PERIPHERAL NEIGHBOURHOODS IN LAGES, SC}

\section{ABSTRACT}

This study investigated the resident's perceptions regarding the urban trees in three peripheral neighbourhoods of Lages, SC, as well as quantify and qualify the urban trees. For this sake, the roads in these neighborhoods were sampled (28.6\% of the roads of Caravaggio, $24.1 \%$ and $25.0 \%$ of Gethal and Penha). Within each selected road, questionnaires with essay and objective questions were applied in randomly selected residences, in order to assess the perception of residents concerning the urban forestry. In the selected roads, all individual trees found were identified, measured and evaluated. In general, the residents of the neighborhoods considered the arborization as reasonable to poor. Although residents recognize some disadvantages of urban trees, they recognize its importance to the well-being and are not satisfied with the performance of municipal government, suggesting a greater investment in leisure. In the area was found lower species richness and a wide use of exotic species, mainly Ligustrum lucidum WT Aiton., an invasive species of natural areas. It is necessary the improvement of both quantity and quality of urban trees by prioritizing the use of regional native species.

Keywords: Urban trees; Ligustrum lucidum; species richness.

\footnotetext{
${ }^{1}$ Graduanda em Engenharia Florestal, Universidade do Estado de Santa Catarina, Departamento de Engenharia Florestal, Lages, SC, alinegros@hotmail.com ${ }^{2}$ Graduanda em Engenharia Florestal, Universidade do Estado de Santa Catarina, Departamento de Engenharia Florestal, Lages, SC, pryprydors@hotmail.com ${ }^{3}$ Graduanda em Engenharia Florestal, Universidade do Estado de Santa Catarina, Departamento de Engenharia Florestal, Lages, SC, karol_acampos@hotmail.com

${ }^{4}$ Doutora em Engenharia Florestal, Universidade do Estado de Santa Catarina, Departamento de Engenharia Florestal, Lages, SC, carol_sil4@yahoo.com.br

${ }^{5}$ Doutor em Engenharia Florestal, Universidade do Estado de Santa Catarina, Departamento de Engenharia Florestal, Lages, SC, higuchip@gmail.com

${ }^{6}$ recebido em 10.03.2011 e aceito para publicação em 15.06.2012
} 


\section{INTRODUÇÃO}

O ser humano almeja o bem estar e o equilíbrio entre o físico e o psicológico, ou seja, uma qualidade de vida adequada. Esta está diretamente relacionada a uma série de fatores, entre os quais a saúde se destaca. Porém, a definição de saúde, segundo a Organização Mundial da Saúde, não é "simplesmente a ausência de doença ou enfermidade”, mas sim "um estado de completo bemestar físico, mental e social”.

O contato com elementos da natureza, como a vegetação arbórea, é um quesito importante para proporcionar esse bem-estar. Segundo Moser et al. (2010a), as árvores podem contribuir para a melhoria da saúde nos aspectos físicos (e.g. melhoria da qualidade do ar, que tem como conseqüência positiva a redução de pessoas com doenças respiratórias, entre outros) e psicológicos, minimizando a monotonia da paisagem por meio das diferentes cores, formas e texturas. Além disso, segundo os mesmos autores, o convívio com a natureza remete a ancestralidade, diminuindo índices de estresse e proporcionando bem estar.

Assim, é importante a construção e a manutenção de praças arborizadas e de ruas com espécies arbóreas de considerável beleza cênica. Estas tornam o ambiente mais atrativo, por propiciar o contato direto dos moradores com um elemento natural (Sheets e Manzer,
1991). Porém, a arborização no Brasil não tem o devido planejamento e manutenção (Milano, 1994). Essa situação se agrava em bairros pobres ou periféricos onde, devido à ausência de preocupação por parte do Poder Público quanto à qualidade e à quantidade de árvores, há o comprometimento dos benefícios que advém da arborização e até a sua inexistência (Veiga et al., 1999). Portanto, estudos nestes bairros são importantes para subsidiar ações que tenham como objetivo o planejamento e a manutenção de uma arborização adequada.

Em Lages, SC, e região, poucos estudos sobre a arborização urbana das cidades foram realizados (Moser et al., 2009; Pinheiro et al., 2009; Reis et al., 2009; Moser et al., 2010a; Moser et al., 2010b), porém, nenhum que englobasse estudos em bairros periféricos, ressaltando a necessidade desse tipo de estudo na região. Assim, este trabalho teve como objetivos: i) avaliar a percepção dos moradores em relação à arborização de três bairros localizados na região periférica da cidade de Lages, SC, e ii) quantificar e qualificar a arborização destes bairros.

\section{MATERIAIS E MÉTODOS}

Descrição e amostragem dos Bairros Caravágio, Gethal e Penha

Foram estudados três bairros localizados na região periférica da cidade de Lages, SC. Lages encontrase na região serrana do estado, possui uma área de 2.630 km² e uma população de 156.737 habitantes (IBGE, 2011). A vegetação nativa da região é formada por floresta com Araucária e campos de altitude que, segundo o IBGE (1992), pode ser classificado, respectivamente, como Floresta Ombrófila Mista e Estepe GramíneoLenhosa.
Para o estudo dos bairros, foram sorteadas ruas para compor a amostra de cada bairro. No Bairro Gethal foram sorteadas $24,1 \%$ das ruas, totalizando sete ruas amostradas, de um total de 29 ruas. No Bairro Penha $25,0 \%$ foram sorteadas, sendo amostradas nove ruas, de um total de 36 ruas. No Bairro Caravágio foram sorteadas $28,6 \%$ das ruas, amostrando-se seis ruas, de um total de 21.

PERCEPÇÃO DOS MORADORES E... 


\section{Percepção da arborização urbana pelos moradores dos Bairros Caravágio, Gethal e Penha}

Para o estudo da percepção da arborização urbana pelos moradores dos bairros avaliados, foram aplicados questionários à população. Em cada bairro, foram selecionadas aleatoriamente cinco residências por rua sorteada. No Bairro Gethal foram selecionadas 35 casas, no Bairro Penha 45 casas e no Caravágio 30 casas.
O sistema de referência utilizado para localização dos bairros e ruas foi o mapa municipal na escala de 1:7500 do ano de 2008, confeccionado pela Prefeitura municipal de Lages. O questionário foi aplicado aos moradores das residências amostradas em abril de 2010, tendo questões objetivas e dissertativas (Tabela 1 ).

TABELA 1. Questionário apresentado aos moradores de bairros periféricos em Lages, SC

TABLE 1. Questionnaire presented to residents of peripherals neighborhoods in Lages, SC

\begin{tabular}{ll}
\hline Questões & Repostas \\
\hline 1 - Há quantos moradores em sua & - \\
residência? & -
\end{tabular}

\begin{tabular}{|c|c|}
\hline \multirow{7}{*}{$\begin{array}{l}2 \text { - Grau de escolaridade do } \\
\text { entrevistado: }\end{array}$} & ( ) analfabeto \\
\hline & ( ) ensino fundamental incompleto \\
\hline & ( ) ensino fundamental completo \\
\hline & ( ) ensino médio incompleto \\
\hline & ( ) ensino médio completo \\
\hline & ( ) ensino superior incompleto \\
\hline & ( ) ensino superior completo \\
\hline \multirow{3}{*}{$\begin{array}{l}3 \text { - Em sua rua, como você considera a } \\
\text { arborização? }\end{array}$} & ( ) muito arborizada \\
\hline & ( ) razoavelmente arborizada \\
\hline & ( ) pouco arborizada \\
\hline \multirow{4}{*}{$\begin{array}{l}4 \text { - Que vantagens são presenciadas na } \\
\text { arborização de sua rua? }\end{array}$} & ( ) sombra \\
\hline & ( ) redução de calor \\
\hline & ( ) redução de poluição \\
\hline & ( ) outras: \\
\hline \multirow{6}{*}{$\begin{array}{l}5 \text { - Quais as desvantagens que você } \\
\text { observa na arborização de sua rua? }\end{array}$} & ( ) sujeira das ruas e calçadas \\
\hline & ( ) sujeira provocada pelos pássaros \\
\hline & ( ) redução da iluminação pública \\
\hline & ( ) problemas com a rede elétrica ou telefônica \\
\hline & ( ) problemas na calçada \\
\hline & ( ) outras: \\
\hline
\end{tabular}


6 - Em relação a áreas verdes, como praças para o lazer, assinale uma das alternativas a baixo:
( ) É importante para o bem estar da população, pois dispõem de espaço para exercícios físicos, contribuindo na qualidade da saúde física e psicológica dos mesmos

( ) Não altera seu cotidiano

( ) É um investimento desnecessário

\begin{tabular}{ll}
\hline $\begin{array}{l}\text { 7- Você colabora com a arborização } \\
\text { do bairro? }\end{array}$ & $\begin{array}{l}\text { ( ) colabora } \\
\text { ( ) não colabora }\end{array}$ \\
\hline 8 - Se colabora, de que forma? & ( ) plantando árvores \\
( ) fazendo a manutenção e podando \\
( ) não danificando \\
( ) outras formas:
\end{tabular}

9 - Que ações deveriam ser realizadas para a melhoria da arborização no bairro e na cidade?

10 - Quais espécies de árvores você gostaria que fossem plantadas em sua rua?

\section{Avaliação da arborização dos Bairros Caravágio, Gethal e Penha}

A arborização dos três bairros foi avaliada utilizando-se as mesmas ruas amostradas. Nestas, foram identificadas, mensuradas e avaliadas todas as árvores presentes nas calçadas, canteiros centrais, praças presente na rua e recuo em frente às residências. As identificações foram feitas por meio de literatura especializada e as espécies foram classificadas em nativas ou exóticas do

\section{RESULTADOS E DISCUSSÃO}

Percepção da arborização urbana pelos moradores dos Bairros Caravágio, Gethal e Penha.

No Bairro Caravágio há, na maioria das casas, três a cinco moradores por residência (Tabela 2). Já nos Bairros
Brasil. Foram medidas as circunferências a altura do peito (CAP, medida a 1,30 $\mathrm{m}$ do solo) e estimadas as alturas das árvores amostradas. Estas foram avaliadas segundo o afloramento de raiz, a interferência na fiação elétrica e se era um indivíduo que deveria ser substituído devido aos problemas apresentados. 
Tabela 2. Freqüência percentual nas classes de números de moradores por residência em três bairros periféricos de Lages, SC Table 2. Percentage frequency in classes of numbers of residents per residence in three peripheral neighborhood of Lages, SC

\begin{tabular}{llll}
\hline Número de moradores por residência & Bairro Caravágio (\%) & Bairro Gethal (\%) & Bairro Penha (\%) \\
\hline 1 a 3 moradores & 16,66 & 28,60 & 11,11 \\
3 a 5 moradores & 83,33 & 28,60 & 33,33 \\
5 a 10 moradores & 0 & 42,60 & 55,56 \\
\hline
\end{tabular}

O grau de escolaridade também variou entre os moradores dos três bairros. No entanto, todos tiveram a predominância do ensino fundamental incompleto, sendo que no Bairro Caravágio, 50\% dos entrevistados possuíam esse grau de escolaridade (Tabela 3). Em contrapartida, nesse mesmo bairro, $16,66 \%$ dos entrevistados possuía ensino superior completo, o maior valor entre os bairros avaliados. É também preocupante o fato de que $20 \%$ dos entrevistados do Bairro Gethal eram analfabetos. Neste bairro, somente 5,71\% tiveram ensino superior completo, semelhante ao valor de $6,67 \%$ de ensino superior completo encontrado no Bairro Penha.

Tabela 3. Grau de escolaridade dos moradores de três bairros periféricos da cidade de Lages, SC

Table 3. Education level of residents in three peripheral neighborhood of Lages, SC

\begin{tabular}{llll}
\hline Grau de escolaridade & Bairro Caravágio (\%) & Bairro Gethal (\%) & Bairro Penha (\%) \\
\hline Analfabeto & 0 & 20,00 & 13,33 \\
Ensino fundamental incompleto & 50,00 & 45,71 & 40,00 \\
Ensino fundamental completo & 0 & 20,00 & 13,33 \\
Ensino médio incompleto & 0 & 8,57 & 0 \\
Ensino médio completo & 33,33 & 0 & 20,00 \\
Ensino superior incompleto & 0 & 0 & 6,67 \\
Ensino superior completo & 16,66 & 5,71 & 6,67 \\
\hline
\end{tabular}

Dessa forma, é possível estabelecer uma relação entre o grau de escolaridade e o número de moradores por residência. Considerando o valor cumulativo dos que possuem grau de escolaridade somente até o ensino fundamental completo, percebe-se uma grande diferença entre os bairros, com o Bairro Caravágio possuindo $50 \%$ dos entrevistados nesta categoria, o Bairro Gethal com 85,71\% dos entrevistados e o Bairro Penha com 66,66\% dos entrevistados. Esses resultados demonstram um menor grau de escolaridade no Bairro Gethal e Penha quando comparado com o Bairro Caravágio, sendo Gethal e Penha, também, os bairros que possuíram o maior número de moradores por residência.

A percepção dos entrevistados em relação à arborização local também variou entre os bairros avaliados (Tabela 4). Os moradores do Bairro Caravágio perceberam menor intensidade de arborização, com 100\%

Aline Gross et al.. 
dos entrevistados respondendo que a rua onde moram são pouco (33,33\%) ou razoavelmente (66,66\%) arborizadas. A maioria dos moradores do Bairro Gethal percebe a rua residente como pouco arborizada (45,71\%). No entanto, $31,42 \%$ percebem como muito arborizada. Os entrevistados do Bairro Penha tiveram a percepção de maior intensidade de arborização, com 40,00\% considerando a rua onde reside muito arborizada e $46,67 \%$ como razoavelmente arborizada. A necessidade de uma maior quantidade de árvores também foi relatada por Vesely (2007), na Nova Zelândia.

Tabela 4. Percepção da intensidade, vantagens e desvantagens da arborização urbana por moradores de três bairros periféricos localizados na cidade de Lages, SC

Table 4. Perception of intensity, advantages and disadvantages of urban trees by residents in three peripheral neighborhood located in the city of Lages, SC

\begin{tabular}{|c|c|c|c|c|c|c|}
\hline & & & $\begin{array}{l}\text { Bairro } \\
\text { (\%) }\end{array}$ & Caravágio & $\begin{array}{l}\text { Bairro Gethal } \\
\text { (\%) }\end{array}$ & $\begin{array}{l}\text { Bairro Penha } \\
(\%)\end{array}$ \\
\hline \multirow{3}{*}{$\begin{array}{l}\text { Intensidade } \\
\text { arborização }\end{array}$} & \multirow{3}{*}{ da } & Muito arborizada & 0 & & 31,42 & 40,00 \\
\hline & & Razoavelmente arborizada & 66,66 & & 22,85 & 46,67 \\
\hline & & Pouco arborizada & 33,33 & & 45,71 & 13,33 \\
\hline \multirow{4}{*}{$\begin{array}{l}\text { Vantagens } \\
\text { arborização }\end{array}$} & \multirow{4}{*}{ da } & Sombra & 83,33 & & 22,22 & 46,66 \\
\hline & & Redução de calor & 16,66 & & 44,44 & 26,66 \\
\hline & & Redução da Poluição & 0 & & 0 & 0 \\
\hline & & Outras & 0 & & 33,33 & 26,66 \\
\hline \multirow{6}{*}{$\begin{array}{l}\text { Desvantagens } \\
\text { arborização }\end{array}$} & \multirow{6}{*}{ da } & Sujeiras das ruas e calçadas & 33,33 & & 44,44 & 40,00 \\
\hline & & Sujeira provocada pelos pássaros & 16,67 & & 0 & 0 \\
\hline & & Redução da iluminação pública & 0 & & 0 & 0 \\
\hline & & Problemas com a rede elétrica ou telefônica & 50,00 & & 11,11 & 26,66 \\
\hline & & Problemas na calçada & 0 & & 22,22 & 13,33 \\
\hline & & Outras & 0 & & 22,22 & 20,00 \\
\hline
\end{tabular}

Embora a interpretação da intensidade de arborização seja subjetiva e sujeita à influência das experiências de cada entrevistado, estes classificam a intensidade de arborização baseado em comparações com outros locais da cidade ou com outras cidades. Percebe-se, portanto, que a maioria da população dos bairros avaliados está insatisfeita com a arborização de sua rua, pois as respostas predominantes variaram de razoavelmente arborizado (66,6\% do Bairro Caravágio e 46,67\% do Bairro Penha) a pouco arborizada $(45,71 \%$ do Bairro Gethal).
Entre as vantagens da arborização urbana, houve predominância das repostas com a vantagem "sombra" nos Bairros Caravágio (83,33\% dos entrevistados) e Penha (46,66\% dos entrevistados). No Bairro Gethal, 44,44\% apontaram como vantagem da arborização a redução de calor. Esta percepção está de acordo com a realidade, pois, a redução da incidência direta de luz solar e o aumento da umidade relativa do ar, proporcionados pela arborização urbana, podem reduzir até $4^{\circ} \mathrm{C}$ a temperatura ambiente (Biondi, 1990; Lombardo, 1990; Milano \& Dalcin, 2000). A sombra e a redução do calor 
são vantagens predominantes em grande parte dos estudos que avaliam a percepção dos moradores quanto à arborização urbana, tanto no Brasil (e.g. Malavasi \& Malavasi, 2001; Roppa et al., 2007; Araújo et al., 2010), quanto no exterior (e.g. Lorenzo et al., 2000). No questionamento sobre as desvantagens da arborização urbana, houve predominância de respostas dos moradores do Bairro Caravágio (50,00\%) no quesito problemas causados na rede elétrica ou telefônica. Na maioria das vezes, estes problemas são causados pela falta de planejamento no plantio da árvore, precariedade na manutenção, com podas ou e escolha equivocada da espécie para o espaço urbano disponível. A escolha da espécie arbórea para ser plantada no ambiente urbano deve ser compatível com o espaço tridimensional disponível, assim como respeitando-se os elementos urbanos presentes.

A maioria dos morados dos Bairros Gethal (44,44\%) e Penha (40,00\%) concordaram que a maior desvantagem da arborização urbana é a sujeira das ruas e calçadas causada pela queda de folhas e frutos. Outros autores, como Lorenzo et al. (2000), Malavasi e Malavasi (2001),
Roppa et al. (2007) encontraram resultados semelhantes, com a maioria dos moradores inventariados apontando também a sujeira causada pelas árvores como a maior desvantagem da arborização. Uma alternativa para amenizar este tipo de problema seria a utilização na arborização de espécies de folhas perenes.

De forma geral, a percepção dos moradores é de que as áreas verdes são importantes para o bem estar da população, pois são entendidas como locais de atividades de lazer ao ar livre (Tabela 5). Porém, no Brasil, apesar do reconhecimento acadêmico da importância das áreas verdes urbanas e da percepção de muitas pessoas de seus benefícios, há uma tendência de se "economizar espaços para o lazer”, principalmente nas zonas urbanas mais pobres e, como conseqüência, pode-se causar a deterioração da qualidade de vida dos habitantes. Segundo Silva (2005), as áreas verdes no ambiente humano proporcionam diversos tipos de benefícios, tais como a proteção da qualidade da água, atenuação da poluição, conforto térmico, sonoro e lumínico, quebra da monotonia das cidades, abrigo à fauna e amenização do desconforto psicológico causado pelas massas edificadas.

Tabela 5. Percepção da importância das áreas verdes por moradores de três bairros periféricos da cidade de Lages, SC Table 5. Perception of the importance of green areas for residents of three peripheral neighborhood of Lages, SC

\begin{tabular}{|c|c|c|c|}
\hline & Bairro Caravágio (\%) & Bairro Gethal (\%) & Bairro Penha (\%) \\
\hline $\begin{array}{l}\text { Importante para o bem estar da população, pois } \\
\text { dispõem de espaço para exercícios físicos, } \\
\text { contribuindo na qualidade da saúde física e } \\
\text { psicológica dos mesmos }\end{array}$ & 91,4 & 91,7 & 92,3 \\
\hline Não altera seu cotidiano & 0 & 0 & 0 \\
\hline Investimento desnecessário & 8,6 & 8,3 & 7,8 \\
\hline
\end{tabular}

Outra questão investigada foi sobre a colaboração dos moradores entrevistados com a arborização do seu bairro e, se sim, de que forma fazem isso. $83,33 \%$ dos moradores do Bairro Caravágio relataram que colaboram; do Bairro Gethal, 66,67\% disseram que fazem essa colaboração e 73,33\% dos moradores do Bairro Penha relataram sua contribuição (Tabela 6). 
Tabela 6. Porcentagem de moradores que realizam a colaboração com a arborização do seu bairro e porcentagem das formas de colaboração dos que colaboram, em estudo realizado em três bairros periféricos na cidade de Lages, SC

Table 6. Percentage of residents who perform collaboration with the urban trees in his neighborhood and the percentage of cooperation form in a study conducted in three peripheral neighborhood in Lages, SC

\begin{tabular}{|c|c|c|c|c|c|}
\hline & & $\begin{array}{l}\text { Bairro } \\
\text { (\%) }\end{array}$ & Caravágio & $\begin{array}{l}\text { Bairro Gethal } \\
\text { (\%) }\end{array}$ & $\begin{array}{l}\text { Bairro Penha } \\
\text { (\%) }\end{array}$ \\
\hline \multirow{4}{*}{$\begin{array}{l}\text { Colaboração nos } \\
\text { bairros }\end{array}$} & Plantando árvores & 16,67 & & 29,2 & 58,67 \\
\hline & Fazendo manutenção e podando & 66,66 & & 31,17 & 14,66 \\
\hline & Não danificando & 0 & & 6,3 & 0 \\
\hline & Outras formas & 0 & & 0 & 0 \\
\hline \multicolumn{2}{|l|}{ Total que colabora } & 83,33 & & 66,67 & 73,33 \\
\hline \multicolumn{2}{|c|}{ Total que não colabora } & 16,66 & & 33,33 & 26,66 \\
\hline
\end{tabular}

As formas de colaboração destacadas podem causar problemas, já que o plantio de espécies inadequadas ao espaço tridimensional disponível pode causar interferências nos elementos urbanos. Além disso, a manutenção inadequada de árvores pode ocasionar efeitos estéticos desagradáveis, como a poda mutiladora, que pode, também, resultar na morte da árvore. Nessas podas, segundo Castro (2004), a copa é danificada, deixando áreas expostas ao ataque de fitopatógenos.

Por isso, os responsáveis pela manutenção e plantio de árvores nas ruas não devem ser os moradores. Segundo Silva (1995), cabe ao poder público, no caso as prefeituras municipais, executar e manter a arborização urbana, que deve estar prevista no plano diretor e lei de uso do solo de cada município ou região metropolitana, observando-se os princípios e limites previstos no art. $2^{\circ}$, parágrafo único do Código Florestal, lei 7.803/89. Além disso, de acordo com relato de Teixeira et al. (2009), por se tratar de uma atividade imprescindível para o bem estar da população, cabe ao Poder Público municipal em sua política de desenvolvimento urbano, criar, preservar e proteger as áreas verdes da cidade, bem como regulamentar o sistema de arborização.

Em relação à questão "que ações deveriam ser realizadas para a melhoria da arborização no bairro e na cidade?”, as respostas variaram pouco, muitos estavam insatisfeitos com a atuação do Poder Publico municipal, sugerindo que os mesmos investissem mais no bem estar e lazer da população. Outros disseram que é importante a organização e manifesto da Associação de Moradores de seu bairro, "pois unidos conseguimos abranger maior espaço e diminuir os danos por vandalismo”. Dentre as espécies arbóreas sugeridas pelos entrevistados para serem plantadas em suas ruas, estão as que os moradores tem mais contado, plantadas em Lages e região. Foram sugeridas tanto espécies exóticas como nativas da região. Percebeu-se que foi levada em consideração, pelos moradores, a beleza da espécie com suas flores vistosas e espécies frutíferas. As espécies sugeridas, em sua maioria, foram: Goiabeira serrana (Acca sellowiana (O.Berg) Burret, nativa da região de Lages), Extremosa (Lagerstroemia indica L., exótica ao Brasil), Ipê-roxo (Handroanthus heptaphyllus (Martius) Mattos, nativo do Brasil, porém exótico à região de Lages), Ipê-amarelo (Handroanthus albus (Cham.) Mattos, nativo da região de Lages), Jacarandá-mimoso (Jacaranda mimosifolia D. Don, exótico ao Brasil),Magnólia (Magnolia liliflora Desr., exótico ao Brasil), Jaboticabeira (Plinia cauliflora (Mart.) Kausel, nativo do Brasil, porém exótica à região de Lages) e Guabiroba (Campomanesia xanthocarpa O.Berg, nativa da região de Lages).

PERCEPÇÃO DOS MORADORES E... 


\section{Avaliação da arborização dos Bairros Caravágio, Gethal e Penha}

A partir do inventário das árvores nos mesmos bairros, procurou-se relacionar a percepção dos moradores e a arborização urbana existente. No Bairro Caravágio foram encontrados 55 indivíduos arbóreos nas ruas amostradas, pertencentes a nove espécies, no Bairro Gethal foram encontrados 52 indivíduos pertencentes a dez espécies e no Bairro Penha 60 árvores distribuídas em 15 espécies (Tabelas 7, 8 e 9). A percepção dos moradores em relação à intensidade da arborização reflete estes valores de abundância encontrados, considerado, pela maioria, razoável nos bairros do Caravágio e Penha, e "pouco arborizada”, no Bairro do Gethal.

Ligustrum lucidum W.T. Aiton. (família Oleaceae) foi a espécie de maior ocorrência nos três bairros avaliados, possuindo a densidade relativa de 32,73\% no Bairro Caravágio, 40,38\% no Bairro Gethal e 30,0\% no Bairro
Penha. Esta espécie ultrapassou a recomendação de Santamour Junior (1990) de porcentagem máxima de ocorrência de indivíduos de uma espécie, que é de $10 \%$ da arborização total. Também ultrapassou a recomendação para o gênero, que é de $20 \%$ e, no caso dos Bairros Caravágio e Gethal, também a recomendação para família botânica, que é de 30\%. Segundo Santamour Junior (1990), estas porcentagens são o limite máximo recomendado para garantir maior diversidade de espécies arbóreas na paisagem urbana a fim de se ter maior proteção contra pragas e doenças. Além disso, de acordo com Moser et al. (2009), a maior diversidade permite que as árvores exerçam melhor sua função ecológica de fornecimento de hábitat e alimento para a fauna, pois permite maior variedade nas relações ecológicas.

Tabela 7. Espécies amostradas e respectivas variáveis mensuradas no Bairro Caravágio em Lages, SC

Table 7. Sampled species and their respective variables measured in Caravágio neighborhood in the municipality of Lages, SC

\begin{tabular}{|c|c|c|c|c|c|}
\hline $\mathrm{O}$ & Família & Nome científico & $\mathrm{N}^{0}$ & CAP & $\mathrm{H}$ \\
\hline $\mathrm{N}$ & Anacardiaceae & Schinus terebinthifolius Raddi & 1 & 33 & 7 \\
\hline $\mathrm{N}$ & Araucariaceae & Araucaria angustifolia (Bert.) Kuntze & 5 & 129 & 15 \\
\hline $\mathrm{N}$ & Arecaceae & Syagrus romanzoffiana (Cham.) Glassman & 10 & 108 & 9 \\
\hline $\mathrm{E}$ & Cupressaceae & Cupressus lusitanica Miller & 3 & 169 & 13 \\
\hline $\mathrm{E}$ & Lythraceae & Lagerstroemia indica L. & 6 & 54 & 3,5 \\
\hline $\mathrm{E}$ & Meliaceae & Melia azedarach L. & 5 & 132 & 8 \\
\hline $\mathrm{E}$ & Oleaceae & Ligustrum lucidum W.T. Aiton. & 18 & 61 & 5 \\
\hline $\mathrm{E}$ & Rosaceae & Eriobotrya japonica (Thunb.) Lindl. & 6 & 18 & 9 \\
\hline $\mathrm{E}$ & Rutaceae & Citrus limon (L.) Burm. f. & 1 & 17 & 3,6 \\
\hline
\end{tabular}


Tabela 8. Espécies amostradas e respectivas variáveis mensuradas no Bairro Gethal em Lages, SC

Table 8. Sampled species and their respective variables measured in Gethal neighborhood in the municipality of Lages, SC

\begin{tabular}{llllll}
\hline O & Família & Nome científico & N $^{\mathbf{0}}$ & CAP & H \\
\hline N & Arecaceae & Butia eriospatha (Mart. ex Drude) Becc. & 1 & 73 & 6 \\
N & Myrtaceae & Psidium cattleianum Sabine & 7 & 56 & 4,7 \\
N & Arecaceae & Syagrus romanzoffiana (Cham.) Glassman & 1 & 111 & 8,5 \\
E & Lyrthaceae & Cuphea gracilis H.B. \& K. & 8 & 19 & 3,5 \\
E & Meliaceae & Melia azedarach L. & 7 & 129 & 9 \\
E & Oleaceae & Ligustrum lucidum W.T. Aiton. & 21 & 53 & 4 \\
E & Pinaceae & Pinus elliottii Engel. & 2 & 93 & 11 \\
E & Rosaceae & Eriobotrya japonica (Thunb.) Lindl. & 2 & 22 & 6,5 \\
E & Rutaceae & Citrus limon (L.) Burm. f. & 1 & 23 & 4 \\
E & Taxodiaceae & Cryptomeria japonica (L. f.) D. Don & 2 & 85 & 9
\end{tabular}

$\overline{\mathrm{O}}$ = origem; $\mathrm{N}$ = nativa do Brasil; $\mathrm{E}$ = exótica; $\mathrm{N}^{0}$ = número de árvores; $\mathrm{CAP}$ = valor médio da circunferência a altura do peito, em cm; $\mathrm{H}$ = altura média, em $\mathrm{m}$.

Tabela 9. Espécies amostradas e respectivas variáveis mensuradas no Bairro Penha em Lages, SC

Table 9. Sampled species and their respective variables measured in Penha neighborhood in the municipality of Lages, SC

\begin{tabular}{|c|c|c|c|c|c|}
\hline O & Família & Nome científico & $\mathbf{N}^{\mathbf{0}}$ & CAP & $\mathbf{H}$ \\
\hline $\mathrm{N}$ & Araucariaceae & Araucaria angustifolia (Bert.) Kuntze & 6 & 118 & 13 \\
\hline $\mathrm{N}$ & Arecaceae & Butia eriospatha (Mart. ex Drude) Becc. & 2 & 50 & 4 \\
\hline $\mathrm{N}$ & Bignoniaceae & Handroanthus albus (Cham.) Mattos & 3 & 107 & 17 \\
\hline $\mathrm{N}$ & Dicksoniaceae & Dicksonia sellowiana Hook. & 2 & 97 & 4 \\
\hline $\mathrm{N}$ & Arecaceae & Syagrus romanzoffiana (Cham.) Glassman & 1 & 106 & 9 \\
\hline $\mathrm{E}$ & Lyrthaceae & Cuphea gracilis H.B. \& K. & 3 & 21 & 3,6 \\
\hline $\mathrm{E}$ & Meliaceae & Melia azedarach L. & 7 & 127 & 7 \\
\hline $\mathrm{E}$ & Myrtaceae & Eucalyptus benthamii Maiden et Cambage & 1 & 96,5 & 11 \\
\hline $\mathrm{E}$ & Myrtaceae & Eucalyptus sp. & 1 & 73 & 7 \\
\hline $\mathrm{E}$ & Oleaceae & Ligustrum lucidum W.T. Aiton. & 18 & 67 & 5 \\
\hline $\mathrm{E}$ & Pinaceae & Pinus taeda L. & 4 & 86 & 10 \\
\hline $\mathrm{E}$ & Platanaceae & Platanus x acerifolia (Aiton) Willd. & 1 & 93 & 11 \\
\hline $\mathrm{E}$ & Rosaceae & Eriobotrya japonica (Thunb.) Lindl. & 4 & 39 & 6 \\
\hline $\mathrm{E}$ & Rutaceae & Citrus limon (L.) Burm. f. & 3 & 26,5 & 4,5 \\
\hline $\mathrm{E}$ & Taxodiaceae & Cryptomeria japonica (L. f.) D. Don & 4 & 93 & 11 \\
\hline
\end{tabular}

$\overline{\mathrm{O}}$ = origem; $\mathrm{N}$ = nativa do Brasil; $\mathrm{E}$ = exótica; $\mathrm{N}^{0}$ = número de árvores; CAP = valor médio da circunferência a altura do peito, em cm; $\mathrm{H}$ = altura média, em $\mathrm{m}$.

PERCEPÇÃO DOS MORADORES E... 
Além da utilização do Ligustrum lucidum na arborização urbana representar um problema devido à alta densidade de indivíduos, esta é uma espécie exótica que, segundo o Instituto Horus (2011), é considerada invasora por competir com espécies nativas em área naturais, ocorrendo de forma subespontânea em remanescentes de florestas naturais. No entanto, apesar dos problemas citados, esta espécie cumpre sua funcionalidade de produção de sombra e redução do calor nos meses quentes, percebida pelos moradores dos três bairros. Isto se deve ao fato desta espécie apresentar copa densa e folhas perenes. Outro problema encontrado nos bairros é a ampla utilização de espécies exóticas na arborização, sendo que a maioria das espécies e dos indivíduos nos três bairros é exótica (Tabelas 7, 8 e 9).

Este é um padrão recorrente encontrado em diferentes estudos no Brasil (e.g. Santos et al., 2010), com o potencial de causar impactos negativos, como a invasão de ambientes naturais adjacentes as cidades. Além disso, as espécies exóticas são utilizadas em ampla densidade em detrimento de espécies nativas. As nativas, que apresentam co-evolução com a fauna da região, podem contribuir para a alimentação da fauna nativa, principalmente a avifauna, servindo, também, para a sua conservação. Além dos problemas mencionados, algumas espécies exóticas, como Melia azedarach, que foi encontrada em todos os bairros estudados, são decíduas e produzem frutos carnosos, com o potencial de gerar maior deposição de matéria orgânica sobre as ruas e calçadas, como foi sugerido pelos moradores.

Grande parte das espécies arbóreas dos bairros é de grande porte, característica refletida pelas grandes dimensões de altura e CAP mensurados. $24 \%$ dos indivíduos avaliados apresentavam afloramento de raízes que prejudicavam construções e calçadas, 38,46\% estavam interferindo na fiação elétrica e 31,82\% são indivíduos que, devido aos problemas apresentados, deveriam ser substituídos. Dessa forma, percebe-se que alguns problemas encontrados pela população, como a interferência na fiação, são aqui confirmados pela avaliação da arborização. Isso resulta na necessidade de constante manutenção das árvores que, algumas vezes, conforme relatado nas entrevistas, é realizada pelos moradores. A poda, por exemplo, é uma conseqüência da utilização de espécies inadequadas ao espaço disponível.

\section{CONCLUSÕES}

De forma geral, a percepção dos moradores refletiu o estado atual da arborização urbana. Além disso, o conhecimento do que é valorizado e o que é visto como sendo negativo na arborização representa importante referência para subsidiar programas de arborização urbana, principalmente no que se refere à escolha de espécies. Para a maioria dos entrevistados, a arborização urbana foi classificada como sendo "pouca” a "razoável”, o que pode estar indicando uma arborização escassa ou má distribuída. Os moradores reconheceram algumas desvantagens da arborização urbana, como a geração de “sujeira” nas ruas e calçadas e danos à rede elétrica ou telefônica, que o inventário demonstrou estarem relacionados ao uso inadequado de algumas espécies, como as decíduas e as de porte não adequado ao espaço tridimensional disponível.

No entanto, os entrevistados reconheceram a importância da arborização sobre o bem-estar, como a produção de sombra e a redução da temperatura nos meses mais quentes. Neste contexto, apesar de Ligustrum lucidum, a espécie de maior número de indivíduos nos três bairros avaliados, desempenhar bem estas funções, recomenda-se a substituição desta espécie por outras nativas, com as mesmas características funcionais, devido ao fato de L.

Aline Gross et al.. 
lucidum ser uma espécie exótica, invasora de áreas naturais.

Há falta de conhecimento da população referente às ações que podem ser realizadas sobre a arborização, sendo necessário um trabalho de educação ambiental para esclarecimento sobre a função dos moradores sobre esta. Além disso, percebe-se pequeno conhecimento da população entrevistada a respeito de espécies arbóreas, principalmente nativas, sendo importante o investimento em ações visando a educação ambiental da população, além da utilização de mudas de espécies nativas na arborização urbana, já que a maioria das espécies e indivíduos encontrados no inventário são exóticos.

É necessária a melhoria da arborização urbana tanto na quantidade como na qualidade, priorizando a utilização de espécies nativas da região, assim como o aumento da riqueza de espécies.

\section{REFERÊNCIAS BIBLIOGRÁFICAS}

ARAÚJO, J. L. O.; ARAÚJO, A. C.; ARAÚJO, A. C. Percepção ambiental dos residentes do Bairro Presidente Médici em Campina Grande-PB, no tocante à arborização local. Revista da Sociedade Brasileira de Arborização Urbana, Piracicaba, v. 5, n. 2, p. 67-81. 2010.

BIONDI, D. Paisagismo. Recife: Imprensa Universitária da UFRP. 183 p. 1990.

CASTRO, N.S. Arborização Urbana: poda, condução e legislação. São Paulo: SBAU, ano XII, n. 1, 2004. 12 p. (Boletim informativo).

IBGE. Manual técnico da vegetação brasileira. Série: Manuais técnicos em geociências n.1. Rio de Janeiro: Fundação Instituto Brasileiro de Geografia e Estatística, 1992. 92 p.

IBGE. Censo 2010. Disponível em: http://www.ibge.gov.br/home/. Acesso em: 13 fev 2011.

INSTITUTO HORUS. Espécies invasoras. Disponível em: http://www.institutohorus.org.br/. Acesso em: 13 fev 2011.

LOMBARDO, M. A. Vegetação e clima. In: $3^{\circ}$ Encontro Nacional sobre Arborização Urbana, 1990. Anais... FUPEF, Curitiba, Paraná, 1990. p. 1-13, 1990.

LORENZO, A. B.; BLANCE, C. A.; QI, Y.; GUIDRY, M. M. Assessing resident's willingness to pay to preserve the community urban forest: a small-city case study. Journal of Arboriculture, Champaign, v. 26, n. 6, p. 319-325, nov. 2000.

MALAVASI, U. C., MALAVASI, M. M. Avaliação da arborização urbana pelos residentes - estudo de caso em Mal. Cândico Rondon - Paraná. Ciência Florestal, Santa Maria, v. 11, n. 1, p. 189-193. 2001.

MILANO, M. S. Arborização Urbana: Plano Diretor. In: Congresso Brasileiro de Arborização Urbana. Anais... São Luiz: SBAU, p. 207-215. 1994.

MILANO, M. \& DALCIN, E. Arborização de vias públicas. Rio de Janeiro. Light. 226 p. 2000.

MOSER, P.; SILVA, A. C.; HIGUCHI, P. Avaliação de áreas verdes no município de Lages, SC. IX Congresso de Ecologia do Brasil, Anais... Setembro de 2009, São Lourenço, MG. 2009.

MOSER, P.; SILVA, A. C.; HIGUCHI, P. Arborização urbana: um encontro da natureza com o meio urbano. Espiral, São Paulo, v. 42, jan./mar. 2010a.

MOSER, P.; SILVA, A. C.; HIGUCHI, P.; SANTOS, E. M.; SCHMITZ, V. Avaliação pós-tempestade da arborização do campus da Universidade do Estado de Santa Catarina em Lages, SC. Revista da Sociedade Brasileira de Arborização Urbana, Piracicaba, v. 5, n. 2, p. 36-46. 2010b. 
PINHEIRO, R.; FRANCHIN, E.; RIBEIRO, R. S.; WOLFF, W.; SILVA, A. C.; HIGUCHI, P. Arborização urbana na cidade de São José do Cerrito, SC: diagnóstico e proposta para áreas de maior trânsito. Revista da Sociedade Brasileira de Arborização Urbana, Piracicaba, v.4, n.4, p.63-78, 2009.

REIS, C. A. M.; SILVA, A. C.; HIGUCHI, P.; SOUZA, S. T.; FERREIRA, C. J. S. M.; MICHELON, B.; MORO, L. Diagnóstico da vegetação arbórea e proposta de arborização do Rio Carahá na cidade de Lages, SC. Revista da Sociedade Brasileira de Arborização Urbana, Piracicaba, v. 4, n. 3, p.130-142, 2009.

ROPPA, C., FALKENBERG, J. R., STANGERLIN, D. M., BRUN, F. G. K., BRUN, E. J. \& LONGHI, S. J. Diagnóstico da percepção dos moradores sobre a arborização urbana na Vila Estação Colônia - Bairro Camobi, Santa Maria - RS. Revista da Sociedade Brasileira de Arborização Urbana, Piracicaba, v. 2, n. 2, p. 11-30. 2007.

SANTAMOUR JUNIOR, F.S. Trees for urban planting: diversity, uniformity, and common sense. In: Metria Conference, 7. , 1990, Lisle. Proceedings... p.57-66. 1990.

SANTOS, A. R.; ROCHA, C. F. D.; BERGALLO, H. G. Native and exotic species in the urban landscape of the city of Rio de Janeiro, Brazil: density, richness and arboreal deficit. Urban ecosystem, v. 13, p. 209-222, 2010.

SHEETS, V.; MANZER, C. Affect, cognition and urban vegetation: Some affects of adding trees along city streets. Environment and Behavior, v. 23, p. 285-304. 1991.

SILVA, J. A. Direito ambiental constitucional. 2. ed. São Paulo: Malheiros, 1995. 243p.

SILVA, P. R. J. A Importância das áreas verdes. CDA - Centro de Distribuição de Amostras - Piracicaba, 2005. Disponível em: http://www.bioagri.com.br/site/_por/index.php. Acesso em: 7 nov 2010.

TEIXEIRA, I. F.; SANTOS, N. R. Z.; BALEST, S. S. Percepção ambiental dos moradores de três loteamentos particulares em Santa Maria (RS) quanto a arborização de vias públicas. Revista da Sociedade Brasileira de Arborização Urbana, Piracicaba, v. 4, n. 1, p. 58-78, 2009.

VEIGA, B. G. A.; COUTINHO, C. L.; MALAVASI, U. C. Planejamento, manejo e aspectos sociais em arborização urbana: o caso do Bairro Ecologia, Seropédica, RJ. Floresta e Ambiente, Seropédica, v. 6, n. 1, p. 144-146, jan./dez. 1999.

VESELY, E. Green for green: The perceveid value of a quantitative change in the urban tree estate of New Zeland. Ecological Economics, v. 63, p. 605-615, 2007. 